Review

\title{
The role of NK cells in fighting the virus infection and sepsis
}

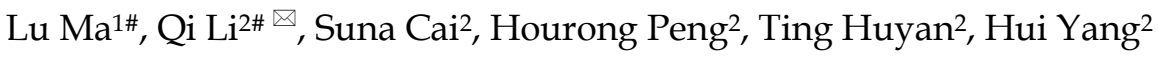 \\ 1. The Hengyang Key Laboratory of Cellular Stress Biology, Institute of Cytology and Genetics, Hengyang Medical School, University of South China, \\ Hengyang, Hunan 421001, China; \\ 2. School of Life Sciences, Northwestern Polytechnical University, Xi'an, 710072, China. \\ \# These authors contributed equally to the article. \\ $\square$ Corresponding author: liqi_1111@nwpu.edu.cn; Tel.: +86-29-88460543
}

(1) The author(s). This is an open access article distributed under the terms of the Creative Commons Attribution License (https://creativecommons.org/licenses/by/4.0/). See http://ivyspring.com/terms for full terms and conditions.

Received: 2021.02.28; Accepted: 2021.06.12; Published: 2021.07.22

\begin{abstract}
Natural killer cells, one of the important types of innate immune cells, play a pivotal role in the antiviral process in vivo. It has been shown that increasing NK cell activity may promote the alleviation of viral infections, even severe infection-induced sepsis. Given the current state of the novel coronavirus (SARS-CoV-2) global pandemic, clarifying the anti-viral function of NK cells would be helpful for revealing the mechanism of host immune responses and decipher the progression of COVID-19 and providing important clues for combating this pandemic. In this review, we summarize the roles of NK cells in viral infection and sepsis as well as the potential possibilities of NK cell-based immunotherapy for treating COVID-19.
\end{abstract}

Key words: Natural killer cells, Viral infection, Sepsis, COVID-19

\section{Introduction}

Natural killer (NK) cells are an important kind of innate immune cell and have been defined as "cytotoxic innate lymphoid cells (ILCs) with the capability of 'natural killing' and antibody-dependent cell-mediated cytotoxicity (ADCC)" [1, 2]. ILCs are the cells have three main features: absence of recombination activating gene (RAG)-dependent rearranged antigen receptors; lack of myeloid cell and dendritic cell phenotypical markers; and their lymphoid morphology [3]. The prototypical ILCs are natural killer (NK) cells and lymphoid tissue-inducer (LTi) cells [4]. Based on the distinct patterns of cytokine production, ILCs could be divided into three groups: group 1 ILCs which have the capability to produce interferon- $\gamma$ (IFN- $\gamma)$; group 2 ILCs which are able to produce $\mathrm{T}$ helper 2 (TH2) cell-associated cytokines, such as interleukin-5 (IL-5) and IL-13; and group 3 ILCs which are capable of producing the TH17 cell-associate cytokines IL-17 and IL-22 [4]. As the mainly ILCs, NK cells play very important roles in immunity against virus-infected and transformed cells [5, 6]. After being discovered in humans and mice in the 1970s, NK cells have received a lot of attention, especially in recent years. In humans, most NK cells circulate in the peripheral blood and represent approximately $15 \%$ of peripheral blood mononuclear cells (PBMCs) [7]. They are found in other tissues/organs as well, such as the spleen, lymph nodes, thymus, liver (where NK cells represent $50 \%$ of resident lymphocytes), skin, uterine decidua and female reproductive tract [8-10].

Traditionally, human NK cells are defined by the expression of CD56 and CD16 and the absence of CD3 $\left(\mathrm{CD} 56^{+} \mathrm{CD} 16^{+} \mathrm{CD} 3^{-}\right)$[11-13]. However, NK cells are not a single type of cell, many NK cell subtypes are produced through a complex development process discriminated by the expression levels of particular biomarkers. Accumulating studies outline a linear model of NK cell development [14], which begins with hematopoietic stem cells (HSCs) $\left(\mathrm{CD} 43^{+}\right)$that successively differentiate into lymphoid-primed multipotential progenitors (LPMP) $\left(\mathrm{CD}^{+} 4^{+} \mathrm{CD} 45 \mathrm{RA}^{+}\right.$ 
$\mathrm{CD}^{+} 0^{+}$and common lymphoid progenitors (CLP) $\left(\mathrm{CD} 34{ }^{+} \mathrm{CD} 45 \mathrm{RA}^{+} \mathrm{CD} 117\right)$, followed by the development of $\mathrm{T} / \mathrm{NK}$-committed progenitors with an $\mathrm{NK} 1.1^{+} \mathrm{CD} 117^{+} \mathrm{CD} 44^{+} \mathrm{CD} 25^{+}$phenotype. T/NKcommitted progenitors can develop into $\mathrm{T}$ lymphocytes in a thymic microenvironment; in contrast, when they are co-cultured with bone marrow-derived stromal cells, they can develop into mature NK cells [15]. After the acquisition of CD94 expression, T/NK-committed progenitors develop into the CD56 ${ }^{\text {bright }} \mathrm{NK}$ cell subset. Following the downregulation of CD94, acquisition of CD16 and killer immunoglobulin-like receptor (KIR) expression, these cells are defined as the CD56 $6^{\mathrm{dim}} \mathrm{NK}$ cell subset [16]. In the branch model of NK cell development, LPMPs could differentiate into CLPs or common myeloid progenitors (CMPs), both of which can differentiate into NK cell progenitors [14]. CD56 bright and CD56 dim NK cells are the major subsets of NK cells, among which canonical CD56 dim NK cells display higher cytotoxicity toward tumor and infected cells with high perforin and granzyme expression levels [17]. Meanwhile, CD56 bright NK cells have less cytotoxicity that secrete low levels of perforin and granzymes but produce several cytokines (i.e., IL-5, IL-10, IL-13 and GM-CSF) and chemokines (MIP-1a, MIP-1 $\beta$, IL-8 and RANTES) and exert an immunoregulatory effect under inflammatory conditions [18-20].

NK cells were presumed to be a relatively homogenous lymphocyte population, particularly compared to T lymphocytes and B cells. However, based on advanced analytical techniques, new evidence has indicated that NK cells actually exhibit a high level of heterogeneity. The data from mass spectrometry/flow cytometry revealed estimated 6,000-30,000 phenotypic populations of NK cells in the peripheral blood of one individual [21]. Although researchers have not determined if the numerous phenotypes of NK cells are in mature and stable states or in a transition state of development, it is undeniable that NK cells are highly heterogeneous and play a more complex role in immune regulation than expected.

\section{NK cells in viral infection}

\section{The strategies of NK cells to discriminate viruses}

NK cells are major antiviral lymphocytes that substantially contribute to the host innate immune system and inflammatory cytokine production. In the early phase of infections, NK cells rapidly respond to pathogens before the development of adaptive immune responses [22, 23]. The underlying mechanism may relate to the short life span and fast regeneration of NK cells [24]. NK cells could be activated in response to infection by different viruses including Zika virus (ZIKV) [25], influenza virus [26], hepatitis $C$ virus [27], dengue virus [28], hantavirus [29], and tick-borne encephalitis virus [30]. Biron et al. observed increased NK cell proliferation and numbers during an acute infection of lymphocytic choriomeningitis virus (LCMV) in mice [31]. Using high-density RNA sequencing, Lum et al. confirmed NK cell activation during acute ZIKV infection. ZIKV elicits a robust immune response by NK cells, as evidenced by increased IFN- $\gamma$ production and CD107a expression [25]. In an influenza virus infection model, NK cells produced swift and strong responses in mice, which was proven by the rapid production of type I IFNs and inflammatory cytokines. The rapid NK cell response efficiently controlled early pulmonary viral replication and increased survival [32]. These data indicate the important roles of NK cells in antiviral immune responses. Hantavirus infection can cause hemorrhagic fever and strong immune activation, leading a 50\% mortality rate [29]. Hantavirus could also induce increased NK cell expansion in an IL-15-depended manner. The hyperactivation of NK cells induced by hantavirus may lead to the death of uninfected endothelial cells [29], which indicated the double-faced effect of NK cells on the host response to viral infection. The extensive activation of NK cells has also been observed in response to other viral infections. Activated NK cells could limit viral spread, decrease inflammatory response, and play a protective role in acute viral infection [28, 33].

In humans, NK cells express several activating receptors on their surface, including NKG2D, 2B4, NKp80, NKp30, NKp44, NKp46, etc., while 2B4 and NKR-P1C (NK1.1) are the activating receptors in mice [34]. Relying on these receptors, NK cells could rapidly recognize and kill malignant cells and virus-infected cells. Meanwhile, inhibitory receptors, including KIRs, killer cell lectin-like receptor G1 (KLRG1), members of the leukocyte immunoglobulin-like receptor (LIR) family and the NKG2A-CD94 receptor complex expressed in human NK cells and Ly49A/C/I/P expressed in mice, maintain autoimmune tolerance by binding to human leukocyte antigen (HLA), self-MHC-I molecules and related proteins or classical cadherins, $(\mathrm{E}-, \mathrm{N}-$, and R-cadherins) [34-36]. In addition, other inhibitory receptors, including CEACAM1, CD300a, and TIGIT in human NK cells, can discriminate non-MHC-I ligands, which are important for maintaining NK cell homeostasis [37-41].

Whether NK cells trigger cytotoxicity depends 
on the delicate balance between inhibitory and activating signals. Natural cytotoxicity receptors (NCR), including NKp30, NKp44 and NKp46, are the dominant activating receptors in NK cells identifying virus-infected cells [38, 42]. After binding to their ligands, activating receptors recruit immunoreceptors such as tyrosine-based activating motif (ITAM)containing adapters, including DAP10, DAP12,

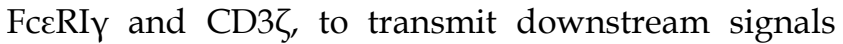
through tyrosine kinases and induce the cytotoxicity of NK cells [38]. When activating signals overpower inhibitory signals, NK cells will kill target cells. In addition, activating receptors are also required for NK cell expansion during viral infection [43]. Influenza virus hemagglutinin (HA) is the first recognized ligand of NCR [38], and poxvirus HA can be recognized by NKp30 and NKp46 [44]. The HA-neuraminidase (HN) of Sendai virus, paramyxoviruses, avian Newcastle disease virus and human parainfluenza virus 3 (HPIV3) is the ligand of NKp44 and NKp46 [38, 45-47]. NKp44 also recognizes the E-protein of dengue virus and West Nile virus [48]. Additionally to directly distinguish viral proteins, NK cells also distinguish the upregulated NKp44L in host cells caused viral infection such as poxviruses, herpesviruses and HIV to trigger cytotoxicity [49-51]. In addition to NCRs, it was recently proven that Toll-like receptor (TLR) can be employed by NK cells to engage pathogen-associated molecular patterns (PAMPs), such as bacteria-associated peptidoglycan, LPS, virus-derived dsRNA and specific DNA with CpG motifs [52]. For example, TLR2 is critical for NK cell activation in response to vaccinia virus (VV) infection by activating the TLR2-MyD88 signaling pathway [53]. TLR3 and TLR4 can recognize mouse-adapted SARS-CoV and induce inflammatory reactions through MyD88 [54] and TRIF-mediated pathways [55]. Therefore, it is worth studying whether there is an analogous recognition pattern between SARS-CoV-2 and host immunocytes.

NKG2D is the receptor that NK cells used to recognize transformed cells and plays an important role in anti-tumor immunological surveillance [56]. It is also a key player in NK cell-mediated cytotoxicity during viral infection. Rather than directly recognizing viral antigens, NKG2D recognizes various MHC I-like ligands, which are often downregulated in virus-infected cells [56, 57]. For example, Kaposi's sarcoma (KS)-associated herpesvirus (KSHV) downregulates the expression of MHC class I on KSHV-infected cells to avoid being recognized by MHC-restricted $\mathrm{CD} 8^{+} \mathrm{T}$ cells, which renders these cells susceptible to being killed by NK cells through the induction of NKG2D-mediated activating signaling [58]. UL16-binding protein
(ULBP), which binds to the human cytomegalovirus (HCMV) glycoprotein UL16, is another key ligand of NKG2D [59]. After HCMV infection, ULBPs expressed by infected cells interact with NKG2D/DAP10 to trigger NK cell-mediated cytotoxicity [60]. Each NK cell receptor interacts with several distinct ligands, but most NKG2D ligands are still unknown [56, 61]. DNAM-1 (CD226) is another important NK cell receptor that mediates anti-tumor immunity [62]; it is also important for NK cells to discriminate viruses. The known ligands of DNAM-1 are poliovirus receptor (PVR) (CD155) and Nectin-2 (CD112), which are latent entry receptors of several viruses to invade cells [63, 64]. Similar to NKG2D, DNAM-1 discriminates ligands on virus-infected cells and triggers NK cell cytotoxicity. TIGIT is a receptor from the same immunoglobulin-like superfamily as DNAM-1, but it exerts inhibitory effects on NK cells [65]. TIGIT binds to the same ligands as DNAM-1 on target cells through a competitive interaction and counteracts NK cell activation [66].

To sum up, there are mainly two strategies of NK cells to be activated in viral infection: one is NK cells activating receptors distinguish the viral protein such as HA, HN and E-protein directly; the other way is the activating receptors distinguish the changed expression of MHC-1 and ULPBs on virus infected cells. Subsequently, the activating signal could be transmitted by activating receptors to trigger NK cells cytotoxicity. The patterns of NK cell activation in viral infection are illustrated in Figure 1.

\section{Viral mechanisms to escape NK cell surveillance}

During the constant battle with the host immune system, viruses have evolved multiple strategies to evade elimination and induce chronic infection. Several viruses, including HCMV [67, 68], mouse CMV [69, 70], zoonotic orthopoxviruses [71], and HIV [72], escape NK cell-mediated elimination by downregulating the expression of NKG2D ligands. For instance, HCMV downregulates the expression of the NKG2D ligands ULBP1, ULBP2, MICB and MICA on infected cells by expressing the viral glycoproteins UL16 and UL142 [68, 73]. Similarly, in individuals with acquired immune deficiency syndrome (AIDS), HIV-1 decreases the cell surface expression of MICA, ULBP1 and ULBP2 in infected cells through Nef protein, which decreases the susceptibility of the virus to NK cell-mediated lysis [72]. KSHV downregulates NKp44L expression on infected cells through the ORF54 gene-encoded protein to escape NK cell-mediated killing [74]. Furthermore, viruses have developed another strategy, upregulating the expression of inhibitor receptor ligands to block NK 
cell activity. For instance, through the activation of the RIGI-IRF3 pathway mediated by IFN- $\beta$, ZIKV increases the expression of MHC-I molecules on infected cells [75]. As mediated by the viral protein MATp1, mouse cytomegalovirus (MCMV) rescues the expression of some MHC-I molecules on infected cells, which are engaged by the inhibitory receptor Ly49. The rescued self MHC-I molecules exhibit increased affinity for Ly 49 and inhibit signaling in NK cells [76].

In addition to downregulating the ligands of NK cell-activating receptors and upregulating the ligands of NK cell-inhibitory receptors on infected cells, the viruses, particularly those readily induce chronic infections, directly impair NK cell cytotoxicity by altering their phenotypes and functions. For example, in chronic hepatitis virus infection, hepatitis $C$ virus (HCV) downregulates NKG2D expression on circulating NK cells through an NS5A-mediated pathway and downregulates NKp30 expression by increasing the levels of an antagonistic NKp30 ligand on HCV-infected cells, which subsequently impairs NK cell-mediated cytotoxicity, ADCC and IFN- $\gamma$ and TNF-a production [77, 78]. In the same way, during chronic hepatitis $B$ virus (HBV) infection, HBV releases the antigens $\mathrm{HBsAg}$ and $\mathrm{HBeAg}$, which directly block NK cell activation, cytokine production and cytotoxic granule release by suppressing the STAT1, NF-kB and p38 MAPK pathways [79]. 2B4 is a $\mathrm{CD} 2$-related receptor belonging to the signaling lymphocyte activation molecule (SLAM) family [80], that is expressed by NK cells, $\gamma \delta T$ cells, basophils, monocytes and a subset of $\mathrm{CD} 8{ }^{+} \alpha \beta \mathrm{T}$ lymphocytes [81]. In patients with persistent $\mathrm{HBV}$ infection, $\mathrm{HBV}$ downregulates the expression of NKG2D and 2B4 on NK cells by increasing TGF- $\beta 1$ expression, subsequently impairing NK cell-mediated cytotoxicity and IFN- $\gamma$ production [82]. In another strategy, human T-cell leukemia virus type 1 (HTLV-1) downregulates the expression of intercellular adhesion molecule 1 (ICAM-1) and ICAM-2 on infected CD4 ${ }^{+} \mathrm{T}$ cells, which subsequently prevents NK cells from adhering to HTLV-1-infected cells and prevents NK cell-mediated death [83]. Furthermore, Japanese encephalitis virus (JEV) inhibits NK cell proliferation by inducing endothelial cell shedding of sHLA-E, which inhibits IL-2- and PMA-mediated ERK 1/2 phosphorylation in NK cell lines [84]. Viruses can also activate immunosuppressive cells, such as myeloid-derived suppressor cells (MDSCs), to impair NK cell activity and block IFN-ץ production [85].

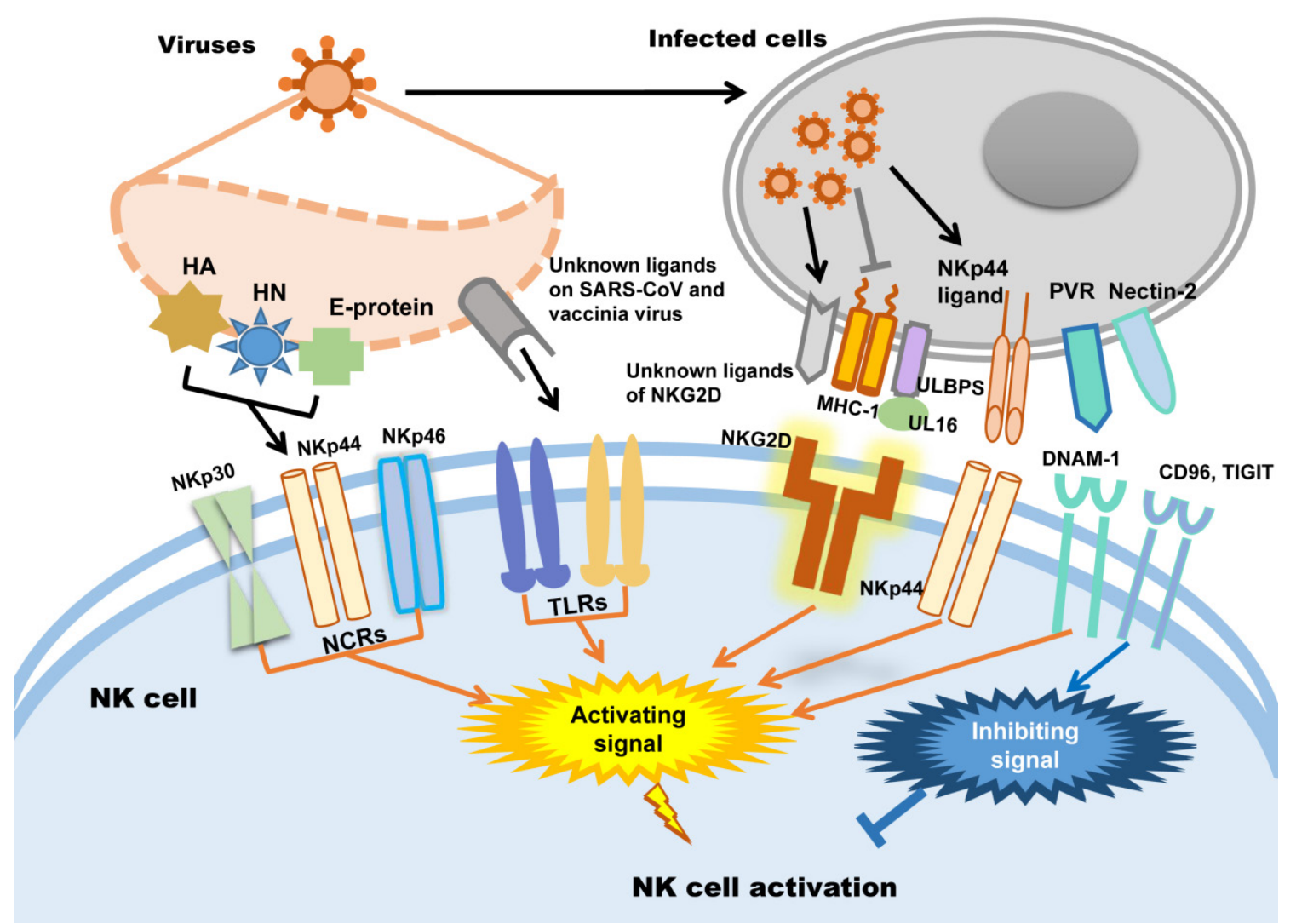

Figure 1. NK cell activation during viral infection. 


\section{Viral infection-related cytokines and signaling pathways in NK cells}

Cytokines and signaling molecules play important roles in the activity and function of NK cells under physiological and pathological conditions. Specifically, IL-2, IL-12, IL-15 [86], IL-18, and IFN- $\gamma$ are the most important cytokines that are secreted by immunocytes and infected tissues [87] to regulate NK cell-mediated cytotoxicity [86]. For example, in VV infection, efficient NK cell activation depends on dendritic cells (DCs) and IL-18 signaling, as well as the TLR2-MyD88 signaling pathway [53, 88]. Meanwhile, both intrinsic and extrinsic STAT1 signaling are indispensable in NK cells responding to VV infection [89]. Furthermore, integrin a2 $\beta 1$ dimers and IFN- $\alpha$ are required for optimal NK cell expansion during viral infection [90, 91]. IFN-a induces the expression of its downstream transcription factors, including STAT1, STAT2 and IRF9, and these transcription factors can induce the transcription of hundreds of IFN-stimulated genes and the "antiviral state" in NK cells [92]. Recently, adrenergic signaling has been proposed to play a novel role in regulating circulating lymphocytes responding to viral infections [93]. Diaz-Salazar et al. reported that depending on IL-12 and STAT4 signaling, NK cells upregulate Adrb2 (which encodes the $\beta 2$-adrenergic receptor) to maintain their proliferative capacity during MCMV challenge [93]. It is beneficial to decipher the underlying complicated signaling networks of NK cell activation for developing strategies to manipulate NK cell function under viral infection, control viral replication in the early stage and prevent severe inflammatory reactions, even sepsis.

Individuals experiencing severe viral infection caused by herpes virus [94], respiratory syncytial virus [95], HCMV, Epstein-Barr virus (EBV), herpes simplex virus (HSV), HBV, HCV and $\operatorname{HIV}[33,96]$ often show impaired NK cell functions. However, NK cells can be a double-edged sword by exerting the unwanted effect of tissue damage in severely infected patients. Fu et al. found that NK cells can mediate hypersensitivity and the pathogenesis of $\mathrm{HCV}$-induced liver injury in mice [97]. By blocking NKG2D and ligand interactions, liver injury was completely prevented in mice model of hepatitis [98]. In a model of an acute viral infection of the central nervous system (CNS), mice deficient in NK cell-mediated cytotoxicity were more resistant to a lethal virulent Semliki Forest virus (vSFV) infection than wild-type mice, suggesting that the cytolytic activity of NK cells may be detrimental under specific circumstances [99].

In conclusion, multiple studies have revealed the intricate functions of NK cells in the immune response to viral infection. Undoubtedly, the expression levels of various NK receptors play important roles in the differential dynamics of NK cell activation and the viral infection process. Intranasal mouse hepatitis virus type 1 (MHV-1) is a group 2 respiratory $\mathrm{CoV}$, and its intranasal infection induces a lung pathology in mice which is similar to the pathological state of patients with severe acute respiratory syndrome (SARS). Using this model, Khanolkar et al. found the contributions of NK cells and type I IFN-mediated signaling to reducing morbidity and mortality of MHV-1-infected mice [100]. In mice infected with mouse hepatitis virus type 3 (MHV3), a coronavirus, the production of NK cells was significantly impaired, which induced the occurrence of fulminant hepatitis [101]. In another study, pigs were pre-infected with porcine reproductive and respiratory syndrome virus (PRRSV) to simulate immunosuppressive respiratory disease. Following repeated infection with porcine respiratory coronavirus (PRCV), significant reductions in innate NK cell-mediated cytotoxic functions were observed in PRRSV and PRCV co-infected pigs [102]. These results indicated the potential role of NK cells in the host immune response to combat CoV infections [100, 102].

\section{NK cells in sepsis}

Sepsis is a pathological process that is induced by a severe systemic infection accompanied by a dysregulated immune response and overexpression of inflammatory factors, which exerts substantial negative effects on health, including damage to multiple organs $[103,104]$. Severe sepsis will induce hypotension and hypoperfusion, and cause lactic acidosis, oliguria, and acute respiratory distress syndrome (ARDS) [105], resulting in an approximately $26 \%$ mortality rate [106].

Many pathogens including bacteria, fungi and viruses can induce sepsis; however, more than $70 \%$ of sepsis cases are caused by bacterial infections [107, 108]. There are no definite diagnostic criteria for discriminating viral sepsis and bacterial sepsis to date, which may lead to unnecessary antimicrobial use [107]. Sporadic studies indicated that elevated procalcitonin levels are more relevant to bacterial infections than viral infections, though related immunological profile data are still scarce for viral sepsis [107, 109]. Except for the well-known overactivation of the immune system during the beginning of sepsis, sepsis-induced immuno suppression cannot be ignored. It was shown that there is a decreased quantity or increased apoptosis of $\mathrm{T}$ and NK cells accompanied by reduced INF- $\gamma$ production in the 'late phase' of sepsis, which can 
cause secondary infection and even death [110, 111].

Relying on the recognition of different PAMPs by TLRs and NCRs $[52,112,113]$, NK cells play very complicated role in sepsis. TLR-4 (Toll-like receptor 4) is a known receptor that recognizes lipopolysaccharide (LPS) from gram-negative bacteria. NK cells display low TLR-4 expression on their surface and moderate TLR4 expression in the cells, which can be activated by PAMPs to produce IFN- $\gamma$ [114]. In a Pseudomonas aeruginosa-induced mouse pneumonia model, splenic NK cell populations were increased accompanied by increased IFN- $\gamma$ secretion [115]. In another mouse model of sepsis that formed by cecal ligation and puncture (CLP) followed by LPS injection, the number of NK cells with low IL-18R expression levels was increased in the mouse liver [116]. Mouse models depleted of NK cells are ideal tools to study NK cell function. In mice infected with pulmonary nontuberculous mycobacteria (NTM), NK cell depletion increased the bacterial load and mortality rate [117]. However, in another study, compared to their wild-type (WT) counterparts, NK cell-deficient mice (IL-15\%- mice) showed higher survival rates and lower levels of pro-inflammatory cytokines [118].

As the main killing proteins secreted by NK cells, the role of granzymes in sepsis should not be ignored. Granzyme-deficient mice (both gzmA-/- and gzmM-/-) showed decreased production of pro-inflammatory cytokines compared to WT mice, which are unlikely to develop endotoxic shock [119]. In addition to their cytotoxic effects, granzymes play an important role in regulating the secretion of pro-inflammatory cytokines [120,121], and this may exacerbate LPS- or endotoxin-mediated cytokine secretion during endotoxic shock [122].

Animal model-based findings revealed the complicated roles of NK cells in the immunopathogenesis of sepsis. However, the existed experiments had produced contradictory results [123, 124]. There are complex reciprocal regulatory pathways between NK cells and other immune cells, including DCs, macrophages, and neutrophils, as well as several cytokines involved during the sepsis process. Researchers have not been able to determine whether NK cells exert a positive or negative effect on sepsis. All the data should be interpreted carefully because of the heterogeneity between mouse models and humans as well as between mouse models themselves.

In a clinical study, unfavorable outcomes including death were observed in patients with severe sepsis whose circulating NK cell number was less than $20 \%$ of the total lymphocyte population. An early increase in the circulating NK cell population will increase the survival rate of patients [125]. In another extensive clinical trial, Gogos et al. found that patients with sepsis have a significantly lower number of circulating NK cells than patients with community-acquired pneumonia (CAP) [126]. According to Forel et al., the number of NK cells $\left(\mathrm{CD} 6^{+} \mathrm{CD}^{-}\right)$in blood samples collected from patients in the ICU is significantly reduced during all stages of sepsis and shows indiscriminate features such as degranulation, as indicated by CD107 or LAMP-1 (lysosomal-associated membrane protein-1) expression and decreased cytotoxicity compared to NK cells from healthy controls [127]. Furthermore, data from an antibody-dependent cell cytotoxicity (ADCC) assay showed that NK cells from patients with sepsis secrete low levels of IFN- $\gamma$ compared with those from their healthy counterparts [127].

In addition to the decreased number, impaired NK cell function has also been observed in clinical studies. As shown in the study by Feng et al., NK cell cytotoxicity dramatically decreased during sepsis, which may result from reduced $\mathrm{CD}^{-}{ }^{-} \mathrm{CD} 56^{+} \mathrm{NK}$ cell cluster differentiation, a shift in the phenotype of NK-activating receptors toward inhibitory receptors, and impaired cytokine production in septic patients [128]. Consequently, the phenotypic changes and impaired functions of NK cells might be one of the underlying causes of immunosuppression during sepsis [128]. Nevertheless, another study reported inconsistent results, in which NK cells isolated from patients with sepsis released larger amounts of IFN- $\gamma$ compared to healthy controls after treatment with LPS [129]. Furthermore, Andaluz-Ojeda et al. found that an increased number of circulating NK cells $(>83$ cells $/ \mathrm{mm}^{3}$ ) is correlated with early death in patients with sepsis [130]. The levels of granzyme proteins (granzyme A, granzyme B, and granzyme K) are all increased in NK cells from patients experiencing sepsis and septic shock who suffer from multiple organ dysfunction, with an increased mortality rate [131-133]. Thus, plasma granzyme levels may be a potential biomarker determining the severity of sepsis [104]. Figure 2 shows the complex roles of NK cells in sepsis.

The significant similarities of immune profile between sepsis and COVID-19 have been reported by Lopez-Collazo et al. [134], or in other words SARS-CoV-2 may be one of the etiological agent causative of sepsis [135]. The common symptoms of sepsis and COVID-19 include excessive inflammation and cytokine storms [136], chronic basal inflammation state [136], high granulocyte-macrophage (GM)-CSF levels in circulating lymphocyte populations, excessive macrophage activation, depletion of lymphocytes, as well as the overexpression of some 
immune checkpoints [134]. C5a is an inflammatory protein, which can bind to the immunocytes expressing $\mathrm{C} 5 \mathrm{aR}$ including NK cells to induce the production of various cytokines and chemokines [137]. A recent study showed that the serum levels of soluble $\mathrm{C} 5 \mathrm{a}$ are increased in SARS-CoV-2 patients [138], which indicate the NK cells may involve in the SARS-CoV-2 induced cytokine storm by C5a regulation. However, another latest study based on single cell sequencing indicated that peripheral monocytes may not contribute to the putative cytokine storm in COVID-19 [139].

The exact role of NK cell in sepsis is very difficult to interpret clearly. First, researchers have not been able to determine whether NK cell dysfunction is a cause or a consequence of sepsis. When other factors induce NK cell dysfunction, exhausted NK cells may not control the progression of sepsis timely and can reverse patient deterioration, or the terrible pathological conditions in sepsis patients could induce NK cell dysfunction. Analogously, hyperactivation of NK cells may be interpreted as the cause of sepsis or the compensatory phenomenon because NK cells actually control sepsis effectively. Although specific effects of NK cells on viral infection and sepsis have not been clearly elucidated, we can still make a bold assumption that highly active NK cells may effectively control viral infection in the early stage by directly killing infected cells or promoting the infiltration of other immune cells, such as neutrophils, $\mathrm{T}$ lymphocytes and $\mathrm{B}$ cells, into the lesion. However, if the initial infection is not controlled timely and effectively, the hyperactivated NK cells will produce excessive levels of pro-inflammatory factors by releasing granzymes, subsequently causing organ injury and even death. Without a doubt, this assumption needs more evidence to be proven or disproven. Additional carefully designed studies should be performed in future to further elucidate the exact role of NK cells in sepsis. For example, if the feasibility and difficulty are not being regarded, the NK cell profile, including the quantity, activity and the ability of NK cells to produce cytokines and cytotoxic granules as well as their specific subtypes, should be monitored constantly in patients with a severe infection and even sepsis. More importantly, clinicians should monitor and analyze the changes in other immunocytes and the complex interactions of each type of immunocyte in the pathological process of sepsis. Single-cell sequencing, a state-of-the-art method with apparent advantages, would be a powerful tool for decoding the specific functions of NK cells and complex mutual regulation with other immune cells in patients with sepsis.

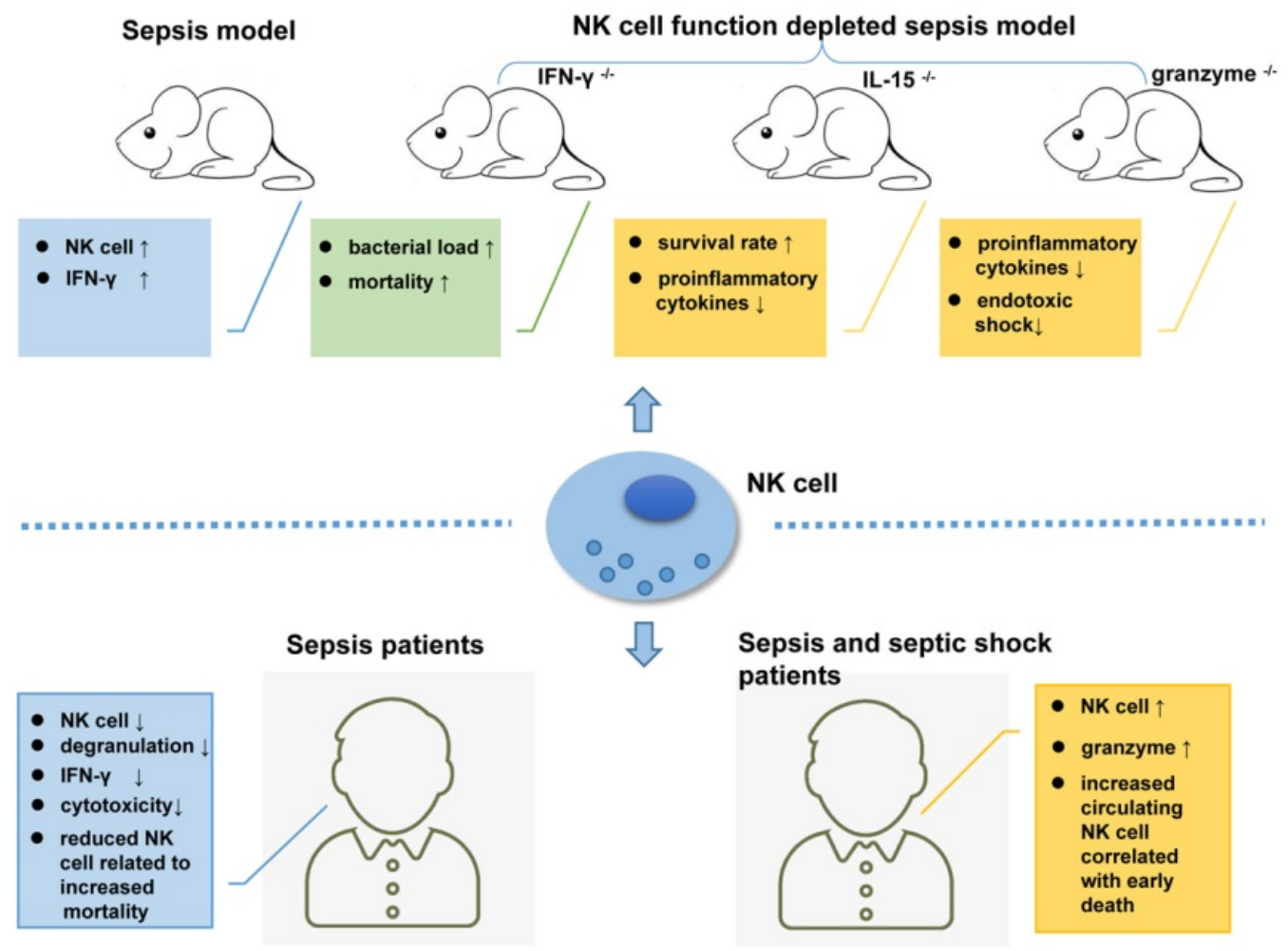

Figure 2. NK cells are key players in the immunopathogenesis of sepsis patients and mouse models. 
Table 1: NK cell-based clinical trials in CAR NK cells from ClinicalTrial.gov (Last accessed: April 28, 2021)

\begin{tabular}{|c|c|c|c|c|c|}
\hline Conditions & Therapeutic(s) & Phase & Patients & Trial identififier & Status \\
\hline HIV Infections & Haploidentical NK cell; N-803 & Phase 1 & 9 & NCT03899480 & Completed \\
\hline HIV & NK cells; IL-2 & Phase 1 & 4 & NCT03346499 & Completed \\
\hline Corona Virus Infection & T memory cells; NK cells & Phase $1 \mid$ Phase 2 & 58 & NCT04578210 & Recruiting \\
\hline SARS-CoV-2 & CYNK-001 cells & Phase $1 \mid$ Phase 2 & 86 & NCT04365101 & Recruiting \\
\hline $\begin{array}{l}\text { CMV Viremia|Transplantation } \\
\text { Infection }\end{array}$ & expanded NK cells & Not available & 10 & NCT04320303 & Recruiting \\
\hline Novel Coronavirus Pneumonia & NK Cells & Phase 1 & 30 & NCT04280224 & Recruiting \\
\hline Covid19 & Off-the-shelf NK Cells (KDS-1000) & Phase 1 | Phase 2 & 54 & NCT04797975 & $\begin{array}{l}\text { Not yet } \\
\text { recruiting }\end{array}$ \\
\hline Covid19|Sars-cov 2 & atural Killer Cells infusion & Phase 1 & 24 & NCT04634370 & $\begin{array}{l}\text { Not yet } \\
\text { recruiting }\end{array}$ \\
\hline COVID & Allogeneic NK transfer & Phase $1 \mid$ Phase 2 & 10 & NCT04344548 & $\begin{array}{l}\text { Not yet } \\
\text { recruiting }\end{array}$ \\
\hline COVID-19 & $\begin{array}{l}\text { NK cells,IL15-NK cells,NKG2D CAR-NK cells,ACE2 } \\
\text { CAR-NK cells,NKG2D-ACE2 CAR-NK cells }\end{array}$ & Phase $1 \mid$ Phase 2 & 90 & NCT04324996 & Recruiting \\
\hline
\end{tabular}

\section{NK cell-based immunotherapy for viral infection}

The pivotal role of NK cell in monitoring and controlling tumors has been extensively confirmed, and NK cell-based tumor immunotherapy has been extensively developed, including autogenous or allogeneic NK cell expansion, gene modification of NK cells and various chimeric antigen receptor (CAR) NK technologies (reviewed by Fang et al.) [140]. Accordingly, NK cell-based immunotherapy is presumptive to be effective at controlling and relieving infections. Because interleukins exerting a positive regulatory effect on NK cells, it may be worth determining whether they could increase NK cell activity during severe infection. Studies have indicated that IL-23 is beneficial for reverting sepsis-associated immunosuppression by activating both NK cells and DCs, and further stimulating protective $\mathrm{T}$ cell immune responses [141, 142]. Additionally, IL-12 and IL-27 may have analogous therapeutic potential with IL-23 for alleviating sepsis $[142,143]$. PD-1 (programmed death receptor-1), also named CD279, is a well-known immune checkpoint that is mainly expressed on T lymphocytes and NK cells. By initiating lymphocyte apoptosis, PD-1 induces immunosuppression and prevents hyperactivation of lymphocytes [144]. Both PD-1 and its ligand PD-L1 (programmed death receptor ligand 1) are highly expressed on lymphocytes from patients with sepsis, which may partially explain the sepsis-associated immunosuppression and increased mortality [145-146]. Therefore, PD-1 antibodies have been used to treat sepsis in mouse models. Shindo et al. found that anti-PD-L1 peptide compound 8 treatment doubled the survival rate of mice with sepsis [148]. Chang et al. and Patera et al. assessed the therapeutic effects of anti-PD-1 and anti-PD-L1 antibodies separately by isolating and culturing lymphocytes from septic patients in vitro. These antibodies increased the survival rate of immunocytes and the production of IFN- $\gamma$ and IL-2 by NK cells [145, 149]. Corresponding clinical experiments are in progress (ClinicalTrial.gov\# NCT02576457). In addition to the PD-1/PD-L1 recognition system, other immune checkpoints, such as cytotoxic T lymphocyte antigen-4 (CTLA-4), $\mathrm{T}$ cell membrane protein-3 (TIM-3), lymphocyte activation-gene-3 (LAG-3) and 2B4, are upregulated during the course of sepsis [150]. Studies focused on the therapeutic effects of these immune checkpoints on sepsis have been conducted in mouse models [151, 152], and clinical trials have shown promising results [153]. Therefore, the specific inhibitors or antibodies targeting immune checkpoints may be ideal candidates for ameliorating and treating sepsis.

CAR is a strategy in which immune cells ( $T$ lymphocytes or NK cells) were engineered by gene fusion and transfection to express a CAR protein that constitutes an antigen-binding region $(\mathrm{scFv})$, transmembrane region and signal transduction region. The $\mathrm{scFv}$ fragment is extracellularly presented to recognize and bind tumor antigens, and the intracellular signal transduction region transmits activating signals in immunocytes [154]. CAR therapy significantly improves the killing effects of immune cells on tumors and has been used in tumor immunotherapy clinically. In addition to tumor therapy, CAR-T cell-based treatments targeting severe viral infections, such as HIV in AIDS [155-159, ClinicalTrial.gov\# NCT03240328 and NCT01013415], HBV infection [160-162] and infection with HCMV [163], have been developed and analyzed in animal models and clinical trials. In an in vitro trial, canine NK cells isolated from PBMCs of normal dogs were expanded; these cells produced large amounts of IFN- $\gamma$ and exhibited dose-dependent cytotoxicity toward canine distemper virus (CDV)-infected Vero 
cells. Pretreatment with anti-CDV serum from hyperimmunized dogs enhanced the ADCC of NK cells against CDV-infected Vero cells. These results emphasize the potential effect of expanded NK cells for treating CDV infection [164]. All of these examples illuminate the possibility of using NK cell-based immunotherapy strategies, including in vitro amplification and each type of CAR method, for treating severe infections and even sepsis. To date, NK cell or CAR-NK cell-based immunotherapy for viral infection are emerging gradually and the related clinical trials were summarized in Table 1.

\section{Fighting COVID-19, do NK cells provide opportunities?}

At the end of 2019, the novel coronavirus (SARS-CoV-2) emerged and has rapidly spread across the world. The COVID-19 has killed more than three million individuals globally till April 2021. In China, the mortality rate is substantially increased to $6.4 \%$ when the patient is greater than 60 years old compared to lower than $1 \%$ in young people [165]. When the patient is aged 80 years or older, the mortality rate increases to $18.4 \%$ [165]. It has been proven that aging can induce immune dysregulation by decreasing cell-mediated immune function and humoral immune responses [166-168]. Specifically, with aging, NK cells showed the profile of decreasing of immature CD56 bright $\mathrm{NK}$ cells and the increasing of highly differentiated CD56 dim CD57 ${ }^{+}$NK cells [169, 170], as well as downregulation of NKG2A [171] and concomitant the upregulation of KIR family members [172]. This phenomenon indicated the impaired proliferation ability and increased cytotoxic capacity and ADCC of NK cells in elder people [173]. Therefore, the role of NK cells in significant correlation between aging and death in COVID-19 is still waiting to be revealed. Other factors that significantly increasing the mortality rate are various basic diseases, including hypertension, diabetes, respiratory system, renal and lung diseases [174]. The main causes of death include excessive inflammation induced by a proinflammatory cytokine storm, disseminated intravascular coagulation (DIC) and thrombus-induced pulmonary dysfunction that subsequently induce ARDS [174] and multiple organ dysfunction (MODS) [175]. Similar to SARS and MERS (Middle East respiratory syndrome coronavirus) [176], a reduced number of lymphocytes, particularly $\mathrm{CD}^{+}{ }^{+} \mathrm{CD} 8{ }^{+} \mathrm{T}$ lymphocytes, has been detected in patients during the early stage of COVID-19; reduced lymphocytes are also an important signal predicting disease severity [177, 178].

Clinical study reported that $\mathrm{NK}$ and $\mathrm{CD} 8^{+} \mathrm{T}$ cells were both found to be markedly decreased in patients with SARS-CoV-2 infection [179, 180]. In addition, asymptomatic patients showed higher counts of lymphocytes, T cells, B cells, and NK cells compared to the symptomatic COVID-19 patients [181, 182]. Specifically, $\mathrm{NK}$ and $\mathrm{CD}^{+} \mathrm{T}$ cell activity was impaired by overexpression of the inhibitory receptor NKG2A in COVID-19 patients [179, 180]. In a latest studies, NK cells were proved activated across distinct subsets in peripheral blood of COVID-19 patients by using multi-color flow cytometry and single-cell RNA sequencing, which was hallmarked by high expression of perforin, NKG2C, and Ksp37 [183]. However, another study using single-cell sequencing indicated that both CD56 dim and CD56 bright NK cells were depleted in COVID-19 samples as well as NK cells appeared exhausted based on expression of LAG3, PDCD1 and HAVCR2 in patients with COVID-19 [139]. The in vitro study indicated the SARS-CoV-2 can induce NK cells exhaustion via Spike 1 protein binding to the HLA-E of lung epithelial cells and trigger HLA-E/NKG2A pathway [184]. These results indicate the important role of NK cells in pathological COVID-19 processes. Nevertheless, more studies focusing on the role of NK cells in SARS-CoV-2 infection are urgently needed, which will be beneficial for developing effective countermeasures for SARS-CoV-2 infection.

Last but not least, few pioneering clinical trials using NK cells to treat COVID-19 patients are ongoing (ClinicalTrial.gov\# NCT04344548, NCT04365101, NCT04280224), as well as an NKG2D-ACE2 CAR-NK based trail (ClinicalTrial.gov\# NCT04324996). These works will be expected to give direct and strong evidence on the effect of NK cell therapy in combating COVID-19. However, some issues should be considered; for example, when is the optimum time to administer NK cells to patients? If uncontrolled inflammation has occurred, the increased NK cells and their hyperactivation may further exacerbate the inflammatory response and cause more damage. The immune environment and cytokine milieu in patient are unique, which may induce unknown and uncontrollable immune reaction of NK cells. Additionally, NK cells from COVID-19 patients must be utilized in biosafety level 3 facilities, which are rare, and the operation may increase the infection risk to operators.

Another strategy is to develop an NK cell-based vaccine targeting SARS-CoV-2. Memory is one of feature of adaptive immune responses of antigen-specific $\mathrm{T}$ and $\mathrm{B}$ lymphocytes, which provides the ability to evoke a rapid and effective response to secondary infections [185]. The 'memory function of NK cells' is a concept that has only been proposed 
recently, stating that NK cells have memory-like, antigen-specific, long-lived adaptive immune responses [186, 187]. Evidence shows that in T- and B-cell-deficient mice, adoptive transfer of virus-sensitized hepatic NK cells into naive recipient mice enhanced the survival of the mice after lethal challenge with the same sensitizing virus [188]. In humans, there are epigenetic modifications and antibody-dependent expansion of memory-like NK cells in HCMV-infected individuals [189]. Likewise, NK cells from CMV- and EBV-infected individuals have the ability to recognize autologous B cells loaded with virus-derived peptides and exhibit antigen-specific cytotoxicity [190]. Based on these findings, it is worth determining whether administration of pre-expanded autogenous NK cells challenged with inactivated SARS-CoV-2 or its spike protein provide a specific amount of immunity and protection. More studies are needed to elucidate the pathology of COVID-19 and the interaction of SARS-CoV-2 with immunocytes. Animal models that reproduce the clinical features of COVID-19 are developing fast, which might significantly help people to combat this disease [191].

\section{Acknowledgments}

This research was funded by the Fundamental Research Funds for the Central Universities (No. 3102020smxy007), China Postdoctoral Science Foundation funded project (No.2020M671065), Seed Foundation of Innovation and Creation for Graduate Students in Northwestern Polytechnical University (Grant no. CX2020257), Hunan Provincial Key Research and Development Program (No. 2019SK2124) and COVID-19 Emergency Response Project from University of South China (2020 \#9 and \#10)).

\section{Author Contributions}

$\mathrm{Lu} \mathrm{Ma}$ and Qi Li conceived the idea; Lu Ma, Qi Li, Suna Cai, Hourong Peng, Ting Huyan and Hui Yang wrote the manuscript; Qi Li designed the illustrations.

\section{Competing Interests}

The authors have declared that no competing interest exists.

\section{References}

1. Orange JS. Natural killer cell deficiency. J Allergy Clin Immunol. 2013; 132: 515-25.

2. Cerwenka A, Lanier LL. Natural killer cell memory in infection, inflammation and cancer. Nat Rev Immunol. 2016; 16: 112-23.

3. Spits $\mathrm{H}$, Cupedo T. Innate lymphoid cells: emerging insights in development, lineage relationships, and function. Annu Rev Immunol. 2012; 30: 647-75.

4. Spits H, Artis D, Colonna M, Diefenbach A, Di Santo JP, Eberl G, et al. Innate ymphoid cells--a proposal for uniform nomenclature. Nat Rev Immunol. 2013; 13: 145-9.
5. Barrow AD, Edeling MA, Trifonov V, et al. Natural killer cells control tumor growth by sensing a growth factor. Cell. 2018; 172: 534-548.e519.

6. Jost S, Altfeld M. Control of human viral infections by natural killer cells. Annu Rev Immunol. 2013; 31: 163-94.

7. Blum KS, Pabst R. Lymphocyte numbers and subsets in the human blood. Do they mirror the situation in all organs? Immunology letters 2007; 108: 45-51.

8. Seillet C, Belz GT, Huntington ND. Development, homeostasis, heterogeneity of NK cells and ILC1. Curr Top Microbiol Immunol. 2016; 395: 37-61.

9. Vosshenrich CA, Garcia-Ojeda ME, Samson-Villeger SI, et al. A thymic pathway of mouse natural killer cell development characterized by expression of GATA-3 and CD127. Nat Immunol. 2006; 7: 1217-24.

10. Fehniger TA, Cooper MA, Nuovo GJ, Cella M, Facchetti F, Colonna M, Caligiuri MA. CD56bright natural killer cells are present in human lymph nodes and are activated by T cell-derived IL-2: a potential new link between adaptive and innate immunity. Blood. 2003; 101: 3052-7.

11. Lanier LL, Testi R, Bindl J, Phillips JH. Identity of Leu-19 (CD56) leukocyte differentiation antigen and neural cell adhesion molecule. J Exp Med. 1989; 169: 2233-8

12. Moretta A, Bottino C, Pende D, et al. Identification of four subsets of human CD3-CD16+ natural killer (NK) cells by the expression of clonally distributed functional surface molecules: correlation between subset assignment of NK clones and ability to mediate specific alloantigen recognition. J Exp Med. 1990; 172: 1589-98.

13. Ritz J, Schmidt RE, Michon J, Hercend T, Schlossman SF. Characterization of functional surface structures on human natural killer cells. Adv Immunol. 1988; 42: 181-211.

14. Cichocki F, Grzywacz B, Miller JS. Human NK cell development: one road or many? Front Immunol. 2019; 10: 2078 .

15. Carlyle JR, Michie AM, Furlonger C, Nakano T, Lenardo MJ, Paige CJ, Zuniga-Pflucker JC. Identification of a novel developmental stage marking lineage commitment of progenitor thymocytes. J Exp Med. 1997; 186: 173-82.

16. Yu J, Freud AG, Caligiuri MA. Location and cellular stages of natural killer cell development. Trends Immunol. 2013; 34: 573-82.

17. Schlums, H, Cichocki, F, Tesi, B et al. Cytomegalovirus infection drives adaptive epigenetic diversification of NK cells with altered signaling and effector function. Immunity. 2015; 42: 443-56

18. Bluman EM, Bartynski KJ, Avalos BR, Caligiuri MA. Human natural killer cells produce abundant macrophage inflammatory protein- 1 alpha in response to monocyte-derived cytokines. J Clin Invest. 1996; 97: 2722-7.

19. Fehniger TA, Shah MH, Turner MJ, VanDeusen JB, Whitman SP, Cooper MA, Suzuki K, Wechser M, Goodsaid F, Caligiuri MA. Differential cytokine and chemokine gene expression by human NK cells following activation with IL-18 or IL-15 in combination with IL-12: implications for the innate immune response. J Immunol. 1999; 162: 4511-20.

20. Roda JM, Parihar R, Magro C, Nuovo GJ, Tridandapani S, Carson WE 3rd Natural killer cells produce $\mathrm{T}$ cell-recruiting chemokines in response to antibody-coated tumor cells. Cancer Res. 2006; 66: 517-26.

21. Horowitz A, Strauss-Albee DM, Leipold M, et al. Genetic and environmental determinants of human NK cell diversity revealed by mass cytometry. Sci Transl Med. 2013; 5: 208ra145

22. Habu S, Akamatsu K, Tamaoki N, Okumura K. In vivo significance of NK cell on resistance against virus (HSV-1) infections in mice. J Immunol. 1984; 133: 2743-7.

23. Holmes KV, Welsh RM, Haspel MV. Natural cytotoxicity against mouse hepatitis virus-infected target cells. I. Correlation of cytotoxicity with virus binding to leukocytes. J Immunol. 1986; 136: 1446-53.

24. Strauss-Albee DM, Blish CA. Human NK cell diversity in viral infection: Ramifications of ramification. Front Immunol. 2016; 7: 66.

25. Lum FM, Lee $\mathrm{D}$, Chua $\mathrm{TK}$, et al. Zika virus infection preferentially counterbalances human peripheral monocyte and/or NK cell activity. mSphere. 2018; 3: e00120-18.

26. Jegaskanda S, Vanderven HA, Tan HX, Alcantara S, Wragg KM, Parsons MS, Chung AW, Juno JA, Kent SJ. Influenza virus infection enhances antibody-mediated NK cell functions via type I interferon-dependent pathways. J Virol. 2019; 93: e02090-18.

27. Oliviero B, Mantovani S, Varchetta S, Mele D, Grossi G, Ludovisi S, Nuti E, Rossello A, Mondelli MU. Hepatitis C virus-induced NK cell activation causes metzincin-mediated CD16 cleavage and impaired antibody-dependent cytotoxicity. J Hepatol. 2017; 66: 1130-7.

28. Gandini M, Petitinga-Paiva F, Marinho CF, Correa G, de Oliveira-Pinto LM, de Souza LJ, Cunha RV, Kubelka CF, de Azeredo EL. Dengue virus Induces NK cell activation through TRAIL expression during infection. Mediators Inflamm. 2017; 2017: 5649214.

29. Braun M, Bjorkstrom NK, Gupta S, Sundstrom K, Ahlm C, Klingstrom J, Ljunggren HG. NK cell activation in human hantavirus infection explained by virus-induced IL-15/IL15Ralpha expression. PLoS Pathog. 2014; 10: e1004521.

30. Blom K, Braun M, Pakalniene J, et al. NK cell responses to human tick-borne encephalitis virus infection. J Immunol. 2016; 197: 2762-71.

31. Biron CA, Turgiss LR, Welsh RM. Increase in NK cell number and turnover rate during acute viral infection. J Immunol. 1983; 131: 1539-45.

32. Zhou K, Wang J, Li A, Zhao W, Wang D, Zhang W, Yan J, Gao GF, Liu W, Fang M. Swift and strong NK cell responses protect 129 mice against high-dose influenza virus infection. J Immunol. 2016; 196: 1842-54.

33. See DM, Khemka P, Sahl L, Bui T, Tilles JG. The role of natural killer cells in viral infections. Scand J Immunol. 1997; 46: 217-24. 
34. Pegram HJ, Andrews DM, Smyth MJ, Darcy PK, Kershaw MH. Activating and inhibitory receptors of natural killer cells. Immunol Cell Biol. 2011; 89: 216-24.

35. Ito M, Maruyama T, Saito N, Koganei S, Yamamoto K, Matsumoto N. Killer cell lectin-like receptor G1 binds three members of the classical cadherin family to inhibit NK cell cytotoxicity. J Exp Med. 2006; 203: 289-95.

36. Montaldo E, del Zotto G, della Chiesa M, Mingari MC, Moretta A, de Maria A, Moretta L. Human NK cell receptors/markers: a tool to analyze NK cell development, subsets and function. Cytometry A. 2013; 83: 702-13.

37. Campbell KS, Purdy AK. Structure/function of human killer cell immunoglobulin-like receptors: lessons from polymorphisms, evolution, crystal structures and mutations. Immunology. 2011; 132: 315-25.

38. Seidel E, Glasner A, Mandelboim O. Virus-mediated inhibition of natural cytotoxicity receptor recognition. Cell Mol Life Sci. 2012; 69: 3911-20.

39. Shibuya A, Nakahashi-Oda C, Tahara-Hanaoka S. Regulation of immune responses by the activating and inhibitory myeloid-associate immunoglobuline-like receptors (MAIR) (CD300). Immune Netw. 2009; 9: $41-5$

40. Stanietsky N, Simic H, Arapovic J, et al. The interaction of TIGIT with PVR and PVRL2 inhibits human NK cell cytotoxicity. Proc Natl Acad Sci U S A. 2009; 106: 17858-63.

41. Orr MT, Lanier LL. Natural killer cell education and tolerance. Cell. 2010; 142: 847-56.

42. Enk J, Mandelboim O. The role of natural cytotoxicity receptors in various pathologies: emphasis on type I diabetes. Front Immunol. 2014; 5: 4.

43. Lee SH, Kim KS, Fodil-Cornu N, Vidal SM, Biron CA. Activating receptors promote NK cell expansion for maintenance, IL-10 production, CD8 T cell regulation during viral infection. J Exp Med. 2009; 206: 2235-51.

44. Jarahian M, Fiedler M, Cohnen A, et al. Modulation of NKp30- and NKp46-mediated natural killer cell responses by poxviral hemagglutinin. PLoS Pathog. 2011; 7: e1002195.

45. Mandelboim O, Lieberman N, Lev M, Paul L, Arnon TI, Bushkin Y, Davis DM, Strominger JL, Yewdell JW, Porgador A. Recognition of haemagglutinins on virus-infected cells by NKp46 activates lysis by human NK cells. Nature. 2001; 409: 1055-60.

46. Jarahian M, Watzl C, Fournier P, Arnold A, Djandji D, Zahedi S, Cerwenka A, Paschen A, Schirrmacher V, Momburg F. Activation of natural killer cells by Newcastle disease virus hemagglutinin-neuraminidase. J Virol. 2009; 83: 8108-21.

47. McQuaid S, Loughran S, Power P, Maguire P, Walls D, Cusi MG, Orvell C, Johnson P. Haemagglutinin-neuraminidase from HPIV3 mediates human NK regulation of T cell proliferation via NKp44 and NKp46. J Gen Virol. 2018; 99: 763-7.

48. Esin S, Batoni G, Counoupas C, Stringaro A, Brancatisano FL, Colone M, Maisetta G, Florio W, Arancia G, Campa M. Direct binding of human NK cell natural cytotoxicity receptor NKp44 to the surfaces of mycobacteria and other bacteria. Infect Immun. 2008; 76: 1719-27.

49. Chisholm SE, Reyburn HT. Recognition of vaccinia virus-infected cells by human natural killer cells depends on natural cytotoxicity receptors. J Virol. 2006; 80: 2225-33.

50. Chisholm SE, Howard K, Gomez MV, Reyburn HT. Expression of ICP0 is sufficient to trigger natural killer cell recognition of herpes simplex virus-infected cells by natural cytotoxicity receptors. J Infect Dis. 2007; 195: $1160-8$

51. Vieillard V, Strominger JL, Debre P. NK cytotoxicity against CD4+ T cells during HIV-1 infection: a gp41 peptide induces the expression of an NKp44 ligand. Proc Natl Acad Sci U S A. 2005; 102: 10981-6.

52. Souza-Fonseca-Guimaraes F, Parlato M, Philippart F, Misset B, Cavaillon JM, Adib-Conquy M. Toll-like receptors expression and interferon-gamma production by NK cells in human sepsis. Crit Care. 2012; 16: R206.

53. Martinez J, Huang X, Yang Y. Direct TLR2 signaling is critical for NK cell activation and function in response to vaccinia viral infection. PLoS Pathog. 2010; 6: e1000811.

54. Sheahan T, Morrison TE, Funkhouser W, Uematsu S, Akira S, Baric RS, Heise MT. MyD88 is required for protection from lethal infection with a mouse-adapted SARS-CoV. PLoS Pathog. 2008; 4: e1000240.

55. Totura AL, Whitmore A, Agnihothram S, Schafer A, Katze MG, Heise MT, Baric RS. Toll-like receptor 3 signaling via TRIF contributes to a protective innate immune response to severe acute respiratory syndrome coronavirus infection. mBio. 2015; 6: e00638-15.

56. Jelencic V, Lenartic M, Wensveen FM, Polic B. NKG2D: A versatile player in the immune system. Immunol Lett. 2017; 189: 48-53.

57. Hansen $\mathrm{TH}$, Bouvier M. MHC class I antigen presentation: learning from viral evasion strategies. Nat Rev Immunol. 2009; 9: 503-13.

58. Thomas M, Boname JM, Field S, Nejentsev S, Salio M, Cerundolo V, Wills M, Lehner PJ. Down-regulation of NKG2D and NKp80 ligands by Kaposi's sarcoma-associated herpesvirus K5 protects against NK cell cytotoxicity. Proc Natl Acad Sci U S A. 2008; 105: 1656-61.

59. Dansako H, Imai H, Ueda Y, Satoh S, Wakita T, Kato N. ULBP1 is induced by hepatitis $\mathrm{C}$ virus infection and is the target of the NK cell-mediated innate immune response in human hepatocytes. FEBS Open Bio. 2018; 8: 361-71.

60. Sutherland CL, Chalupny NJ, Cosman D. The UL16-binding proteins, a novel family of MHC class I-related ligands for NKG2D, activate natural killer cell functions. Immunol Rev. 2001; 181: 185-92.

61. Pazina T, Shemesh A, Brusilovsky M, Porgador A, Campbell KS. Regulation of the functions of natural cytotoxicity receptors by interactions with diverse ligands and alterations in splice variant expression. Front Immunol. 2017; 8: 369.

62. Fuchs A, Colonna M. The role of NK cell recognition of nectin and nectin-like proteins in tumor immunosurveillance. Semin Cancer Biol. 2006; 16: 359-66.

63. Yin, X, Liu, T, Wang, Z, et al. Expression of the inhibitory receptor TIGIT is up-regulated specifically on NK cells with CD226 activating receptor from HIV-infected individuals. Front Immunol. 2018; 9: 2341.

64. Georgiev H, Ravens I, Papadogianni G, Bernhardt G. Coming of age: CD96 emerges as modulator of immune responses. Front Immunol. 2018; 9: 1072

65. Manieri NA, Chiang EY, Grogan JL. TIGIT: a key inhibitor of the cancer immunity cycle. Trends Immunol. 2017; 38: 20-8.

66. Cifaldi L, Doria M, Cotugno N, Zicari S, Cancrini C, Palma P, Rossi P. DNAM-1 activating receptor and its ligands: how do viruses affect the NK cell-mediated immune surveillance during the various phases of infection? Int J Mol Sci. 2019; 20: 3715.

67. Zou Y, Bresnahan W, Taylor RT, Stastny P. Effect of human cytomegalovirus on expression of MHC class I-related chains A. J Immunol. 2005; 174: 3098-104.

68. Chalupny NJ, Rein-Weston A, Dosch S, Cosman D. Down-regulation of the NKG2D ligand MICA by the human cytomegalovirus glycoprotein UL142. Biochem Biophys Res Commun. 2006; 346: 175-81.

69. Hasan M, Krmpotic A, Ruzsics Z, et al. Selective down-regulation of the NKG2D ligand $\mathrm{H} 60$ by mouse cytomegalovirus m155 glycoprotein. J Virol. 2005; 79: 2920-30.

70. Krmpotic A, Hasan M, Loewendorf A, et al. NK cell activation through the NKG2D ligand MULT-1 is selectively prevented by the glycoprotein encoded by mouse cytomegalovirus gene m145. J Exp Med. 2005; 201: 211-20.

71. Campbell JA, Trossman DS, Yokoyama WM, Carayannopoulos LN. Zoonotic orthopoxviruses encode a high-affinity antagonist of NKG2D. J Exp Med. 2007; 204: 1311-7.

72. Cerboni C, Neri F, Casartelli N, Zingoni A, Cosman D, Rossi P, Santoni A, Doria M. Human immunodeficiency virus 1 Nef protein downmodulates the ligands of the activating receptor NKG2D and inhibits natural killer cell-mediated cytotoxicity. J Gen Virol. 2007; 88: 242-50.

73. Dunn C, Chalupny NJ, Sutherland CL, Dosch S, Sivakumar PV, Johnson DC, Cosman D. Human cytomegalovirus glycoprotein UL16 causes intracellular sequestration of NKG2D ligands, protecting against natural killer cell cytotoxicity. J Exp Med. 2003; 197: 1427-39.

74. Madrid AS, Ganem D. Kaposi's sarcoma-associated herpesvirus ORF54/dUTPase downregulates a ligand for the NK activating receptor NKp44. J Virol. 2012; 86: 8693-704.

75. Glasner A, Oiknine-Diian E, Weisblum Y, Diab M, Panet A, Wolf DG, Mandelboim O. Zika virus escapes NK cell detection by upregulating major histocompatibility complex class I molecules. J Virol. 2017; 91: e00785-17.

76. Zeleznjak J, Lisnic VJ, Popovic B, et al. The complex of MCMV proteins and MHC class I evades NK cell control and drives the evolution of virus-specific activating Ly49 receptors. J Exp Med. 2019; 216: 1809-27.

77. Sene D, Levasseur F, Abel M, et al. Hepatitis C virus (HCV) evades NKG2D-dependent NK cell responses through NS5A-mediated imbalance of inflammatory cytokines. PLoS Pathog. 2010; 6: e1001184.

78. Holder KA, Stapleton SN, Gallant ME, Russell RS, Grant MD. Hepatitis C virus-infected cells downregulate NKp30 and inhibit ex vivo NK cell functions. J Immunol. 2013; 191: 3308-18.

79. Yang $Y$, Han Q, Zhang C, Xiao M, Zhang J. Hepatitis B virus antigens impair NK cell function. Int Immunopharmacol. 2016; 38: 291-7.

80. Cannons JL, Tangye SG, Schwartzberg PL. SLAM family receptors and SAP adaptors in immunity. Annu Rev Immunol. 2011; 29: 665-705.

81. McNerney ME, Lee KM, Kumar V. 2B4 (CD244) is a non-MHC binding receptor with multiple functions on natural killer cells and CD8+ T cells. Mol Immunol. 2005; 42: 489-94.

82. Sun C, Fu B, Gao Y, Liao X, Sun R, Tian Z, Wei H. TGF-beta1 down-regulation of NKG2D/DAP10 and 2B4/SAP expression on human NK cells contributes to HBV persistence. PLoS Pathog. 2012; 8: e1002594.

83. Banerjee P, Feuer G, Barker E. Human T-cell leukemia virus type 1 (HTLV-1) p12I down-modulates ICAM-1 and -2 and reduces adherence of natural killer cells, thereby protecting HTLV-1-infected primary CD4+ T cells from autologous natural killer cell-mediated cytotoxicity despite the reduction of major histocompatibility complex class I molecules on infected cells. J Virol. 2007; 81: 9707-17.

84. Shwetank, Date OS, Carbone $E$, Manjunath $R$. Inhibition of ERK and proliferation in NK cell lines by soluble HLA-E released from Japanese encephalitis virus infected cells. Immunol Lett. 2014; 162: 94-100.

85. Goh CC, Roggerson KM, Lee HC, Golden-Mason L, Rosen HR, Hahn YS. Hepatitis C virus-induced myeloid-derived suppressor cells suppress NK cell IFN-gamma production by altering cellular metabolism via arginase-1. J Immunol. 2016; 196: 2283-92.

86. Nguyen KB, Salazar-Mather TP, Dalod MY, van Deusen JB, Wei XQ, Liew FY, Caligiuri MA, Durbin JE, Biron CA. Coordinated and distinct roles for IFN-alpha beta, IL-12, IL-15 regulation of NK cell responses to viral infection. J Immunol. 2002; 169: 4279-87.

87. Vidal SM, Khakoo SI, Biron CA. Natural killer cell responses during viral infections: flexibility and conditioning of innate immunity by experience. Curr Opin Virol. 2011; 1: 497-512.

88. Brandstadter JD, Huang X, Yang Y. NK cell-extrinsic IL-18 signaling is required for efficient NK-cell activation by vaccinia virus. Eur J Immunol. 2014; 44: 2659-66. 
89. Fortin C, Huang X, Yang Y. Both NK cell-intrinsic and -extrinsic STAT1 signaling are required for NK cell response against vaccinia virus. J Immunol. 2013; 191: 363-8.

90. Stotesbury C, Alves-Peixoto P, Montoya B, Ferez M, Nair S, Snyder CM, Zhang S, Knudson CJ, Sigal LJ. Alpha2beta1 integrin is required for optimal NK cell proliferation during viral infection but not for acquisition of effector functions or NK cell-mediated virus control. J Immunol. 2020; 204: 1582-91.

91. Madera S, Rapp M, Firth MA, Beilke JN, Lanier LL, Sun JC. Type I IFN promotes NK cell expansion during viral infection by protecting NK cells against fratricide. J Exp Med. 2016; 213: 225-33.

92. Garcia-Sastre A, Biron CA. Type 1 interferons and the virus-host relationship: a lesson in detente. Science. 2006; 312: 879-82

93. Diaz-Salazar C, Bou-Puerto R, Mujal AM, Lau CM, von Hoesslin M, Zehn D, Sun JC. Cell-intrinsic adrenergic signaling controls the adaptive NK cell response to viral infection. J Exp Med. 2020; 217: e20190549.

94. Biron CA, Byron KS, Sullivan JL. Severe herpesvirus infections in an adolescent without natural killer cells. N Engl J Med. 1989; 320: 1731-5.

95. Noyola DE, Juarez-Vega G, Monjaras-Avila C, Escalante-Padron F, Rangel-Ramirez V, Cadena-Mota S, Monsivais-Urenda A, Garcia-Sepulveda CA, Gonzalez-Amaro R. NK cell immunophenotypic and genotypic analysis of infants with severe respiratory syncytial virus infection. Microbiol Immunol. 2015; 59: 389-97.

96. Arnon TI, Markel G, Mandelboim O. Tumor and viral recognition by natural killer cells receptors. Semin Cancer Biol. 2006; 16: 348-58.

97. Fu Q, Yan S, Wang L, et al. Hepatic NK cell-mediated hypersensitivity to ConA-induced liver injury in mouse liver expressing hepatitis $C$ virus polyprotein. Oncotarget. 2017; 8: 52178-92.

98. Vilarinho S, Ogasawara K, Nishimura S, Lanier LL, Baron JL. Blockade of NKG2D on NKT cells prevents hepatitis and the acute immune response to hepatitis B virus. Proc Natl Acad Sci U S A. 2007; 104: 18187-92.

99. Alsharifi M, Lobigs M, Simon MM, Kersten A, Muller K, Koskinen A, Lee E, Mullbacher A. NK cell-mediated immunopathology during an acute viral infection of the CNS. Eur J Immunol. 2006; 36: 887-96.

100. Khanolkar A, Hartwig SM, Haag BA, Meyerholz DK, Epping LL, Haring JS, Varga SM, Harty JT. Protective and pathologic roles of the immune response to mouse hepatitis virus type 1: implications for severe acute respiratory syndrome. J Virol. 2009; 83: 9258-72.

101. Lehoux M, Jacques A, Lusignan S, Lamontagne L. Murine viral hepatitis involves NK cell depletion associated with virus-induced apoptosis. Clin Exp Immunol. 2004; 137: 41-51.

102. Renukaradhya GJ, Alekseev K, Jung K, Fang Y, Saif LJ. Porcine reproductive and respiratory syndrome virus-induced immunosuppression exacerbates the inflammatory response to porcine respiratory coronavirus in pigs. Viral Immunol. 2010; 23: 457-66.

103. Gul F, Arslantas MK, Cinel I, Kumar A. Changing definitions of sepsis. Turk J Anaesthesiol Reanim. 2017; 45: 129-38.

104. Kumar V. Natural killer cells in sepsis: Underprivileged innate immune cells. Eur J Cell Biol. 2019; 98: 81-93.

105. Munford RS. Severe sepsis and septic shock: the role of gram-negative bacteremia. Annu Rev Pathol. 2006; 1: 467-96.

106. Fleischmann C, Scherag A, Adhikari NK, Hartog CS, Tsaganos T, Schlattmann P, Angus DC, Reinhart K. Assessment of global incidence and mortality of hospital-treated sepsis current estimates and limitations. Am J Respir Crit Care Med. 2016; 193: 259-72.

107. Lin GL, McGinley JP, Drysdale SB, Pollard AJ. Epidemiology and immune pathogenesis of viral sepsis. Front Immunol. 2018; 9: 2147.

108. Phua J, Ngerng W, See K, Tay C, Kiong T, Lim H, Chew M, Yip H, Tan A, Khalizah H, Capistrano R, Lee K, Mukhopadhyay A. Characteristics and outcomes of culture-negative versus culture-positive severe sepsis. Crit Care. 2013; 17: R202

109. Schuetz P, Amin DN, Greenwald JL. Role of procalcitonin in managing adult patients with respiratory tract infections. Chest. 2012; 141: 1063-73

110. Otto GP, Sossdorf M, Claus RA, Rodel J, Menge K, Reinhart K, Bauer M, Riedemann NC. The late phase of sepsis is characterized by an increased microbiological burden and death rate. Crit Care. 2011; 15: R183.

111. Hotchkiss RS, Monneret G, Payen D. Sepsis-induced immunosuppression: from cellular dysfunctions to immunotherapy. Nat Rev Immunol. 2013; 13: 862-74.

112. Athie-Morales V, O'Connor GM, Gardiner CM. Activation of human NK cells by the bacterial pathogen-associated molecular pattern muramyl dipeptide. J Immunol. 2008; 180: 4082-89.

113. Chalifour A, Jeannin P, Gauchat JF, Blaecke A, Malissard M, N'Guyen T, Thieblemont N, Delneste Y. Direct bacterial protein PAMP recognition by human NK cells involves TLRs and triggers alpha-defensin production. Blood. 2004; 104: 1778-83.

114. Kanevskiy LM, Telford WG, Sapozhnikov AM, Kovalenko EI. Lipopolysaccharide induces IFN-gamma production in human NK cells. Front Immunol. 2013; 4: 11

115. Broquet A, Roquilly A, Jacqueline C, Potel G, Caillon J, Asehnoune K. Depletion of natural killer cells increases mice susceptibility in a Pseudomonas aeruginosa pneumonia model. Crit Care Med. 2014; 42: e441-50.

116. Hiraki S, Ono S, Kinoshita M, Tsujimoto $H$, Takahata R, Miyazaki H, Saitoh D, Seki S, Hase K. Neutralization of IL-10 restores the downregulation of IL-18 receptor on natural killer cells and interferon-gamma production in septic mice, thus leading to an improved survival. Shock. 2012; 37: 177-82.
117. Lai HC, Chang CJ, Lin CS, et al. NK cell-derived IFN-gamma protects against nontuberculous mycobacterial lung infection. J Immunol. 2018; 201: 1478-90.

118. Guo Y, Luan L, Patil NK, Wang J, Bohannon JK, Rabacal W, Fensterheim BA, Hernandez A, Sherwood ER. IL-15 enables septic shock by maintaining NK cell integrity and function. J Immunol. 2017; 198: 1320-33.

119. Arias, MA, Jimenez de Bagues MP, Aguilo N, Menao S, Hervas-Stubbs S, de Martino A, Alcaraz A, Simon MM, Froelich CI, Pardo J. Elucidating sources and roles of granzymes $\mathrm{A}$ and $\mathrm{B}$ during bacterial infection and sepsis. Cell Rep. 2014; 8: 420-9.

120. Metkar SS, Menaa C, Pardo J, et al. Human and mouse granzyme A induce a proinflammatory cytokine response. Immunity. 2008; 29: 720-33.

121. Joeckel LT, Bird PI. Are all granzymes cytotoxic in vivo? Biol Chem. 2014; 395: 181-202.

122. Wensink AC, Kok HM, Meeldijk J, Fermie J, Froelich CJ, Hack CE, Bovenschen N. Granzymes A and K differentially potentiate LPS-induced cytokine response. Cell Death Discov. 2016; 2: 16084.

123. Clark SE, Filak HC, Guthrie BS, Schmidt RL, Jamieson A, Merkel P, Knight V, Cole CM, Raulet DH, Lenz LL. Bacterial manipulation of NK cell regulatory activity increases susceptibility to listeria monocytogenes infection. PLoS Pathog. 2016; 12: e1005708.

124. Horowitz A, Stegmann KA, Riley EM. Activation of natural killer cells during microbial infections. Front Immunol. 2011; 2: 88.

125. Giamarellos-Bourboulis EJ, Tsaganos T, Spyridaki E, Mouktaroudi M, Plachouras D, Vaki I, Karagianni V, Antonopoulou A, Veloni V, Giamarellou $\mathrm{H}$. Early changes of CD4-positive lymphocytes and NK cells in patients with severe Gram-negative sepsis. Crit Care. 2006; 10: R166.

126. Gogos C, Kotsaki A, Pelekanou A, et al. Early alterations of the innate and adaptive immune statuses in sepsis according to the type of underlying infection. Crit Care. 2010; 14: R96.

127. Forel JM, Chiche L, Thomas G, et al. Phenotype and functions of natural killer cells in critically-ill septic patients. PLoS One. 2012; 7: e50446.

128. Feng T, Liao X, Yang X, Yang C, Lin F, Guo Y, Kang Y, Li H. A shift toward inhibitory receptors and impaired effector functions on NK cells contribute to immunosuppression during sepsis. J Leukoc Biol. 2020; 107: 57-67.

129. Giannikopoulos G, Antonopoulou A, Kalpakou G, Makaritsis K, Panou C, Papadomichelakis E, Sinapidis D, Theodotou A, Tzagkaraki A, Giamarellos-Bourboulis EJ. The functional role of natural killer cells early in clinical sepsis. APMIS. 2013; 121: 329-36.

130. Andaluz-Ojeda D, Iglesias V, Bobillo F, et al. Early natural killer cell counts in blood predict mortality in severe sepsis. Crit Care. 2011; 15: R243.

131. Zeerleder S, Hack CE, Caliezi C, van Mierlo G, Eerenberg-Belmer A, Wolbink A, Wuillenmin WA. Activated cytotoxic T cells and NK cells in severe sepsis and septic shock and their role in multiple organ dysfunction. Clin Immunol. 2005; 116: 158-65.

132. Rucevic M, Fast LD, Jay GD, Trespalcios FM, Sucov A, Siryaporn E, Lim YP. Altered levels and molecular forms of granzyme $\mathrm{k}$ in plasma from septic patients. Shock. 2007; 27: 488-93.

133. Lauw FN, Simpson AJ, Hack CE, Prins JM, Wolbink AM, van Deventer SJ, Chaowagul W, White NJ, van Der Poll T. Soluble granzymes are released during human endotoxemia and in patients with severe infection due to gram-negative bacteria. J Infect Dis. 2000; 182: 206-13.

134. Lopez-Collazo E, Avendano-Ortiz J, Martin-Quiros A, Aguirre LA. Immune Response and COVID-19: A mirror image of Sepsis. Int J Biol Sci. 2020; 16: 2479-89.

135. Li H, Liu L, Zhang D, Xu J, Dai H, Tang N, et al. SARS-CoV-2 and viral sepsis: observations and hypotheses. Lancet. 2020; 395: 1517-20.

136. Liu J, Li S, Liu J, Liang B, Wang X, Wang H, et al. Longitudinal characteristics of lymphocyte responses and cytokine profiles in the peripheral blood of SARS-CoV-2 infected patients. EBioMedicine. 2020; 55: 102763.

137. Yan C, Gao H. New insights for $\mathrm{C} 5 \mathrm{a}$ and $\mathrm{C} 5 \mathrm{a}$ receptors in sepsis. Front Immunol. 2012; 3: 368.

138. Carvelli J, Demaria O, Vely F, Batista L, Chouaki Benmansour N, Fares J, et al. Association of COVID-19 inflammation with activation of the C5a-C5aR1 axis. Nature. 2020; 588: 146-50.

139. Wilk AJ, Rustagi A, Zhao NQ, Roque J, Martinez-Colon GJ, McKechnie JL, et al. A single-cell atlas of the peripheral immune response in patients with severe COVID-19. Nat Med. 2020; 26: 1070-6.

140. Fang F, Wang W, Chen M, Tian Z, Xiao W. Technical advances in NK cell-based cellular immunotherapy. Cancer Biol Med. 2019; 16: 647-654.

141. O'Dwyer MJ, Mankan AK, White M, Lawless MW, Stordeur P, O'Connell B, Kelleher DP, McManus R, Ryan T. The human response to infection is associated with distinct patterns of interleukin 23 and interleukin 27 expression. Intensive Care Med. 2008; 34: 683-91.

142. Zwirner NW, Ziblat A. Regulation of NK cell activation and effector functions by the IL-12 family of cytokines: the case of IL-27. Front Immunol. 2017; 8: 25.

143. Wu HP, Shih CC, Lin CY, Hua CC, Chuang DY. Serial increase of IL-12 response and human leukocyte antigen-DR expression in severe sepsis survivors. Crit Care. 2011; 15: R224.

144. Chamoto K, Al-Habsi M, Honjo T. Role of PD-1 in immunity and diseases. Curr Top Microbiol Immunol. 2017; 410: 75-97.

145. Patera AC, Drewry AM, Chang K, Beiter ER, Osborne D, Hotchkiss RS. Frontline Science: Defects in immune function in patients with sepsis are associated with PD-1 or PD-L1 expression and can be restored by antibodies targeting PD-1 or PD-L1. J Leukoc Biol. 2016; 100: 1239-54. 
146. Shao R, Fang Y, Yu H, Zhao L, Jiang Z, Li CS. Monocyte programmed death ligand-1 expression after 3-4 days of sepsis is associated with risk stratification and mortality in septic patients: a prospective cohort study. Crit Care. 2016; 20: 124.

147. Wilson JK, Zhao Y, Singer M, Spencer J, Shankar-Hari M. Lymphocyte subset expression and serum concentrations of PD-1/PD-L1 in sepsis - pilot study. Crit Care. 2018; 22: 95.

148. Shindo Y, McDonough JS, Chang KC, Ramachandra M, Sasikumar PG, Hotchkiss RS. Anti-PD-L1 peptide improves survival in sepsis. J Surg Res. 2017; 208: 33-9.

149. Chang K, Svabek C, Vazquez-Guillamet C, et al. Targeting the programmed cell death 1: programmed cell death ligand 1 pathway reverses $\mathrm{T}$ cell exhaustion in patients with sepsis. Crit Care. 2014; 18: R3.

150. Patil NK, Guo Y, Luan L, Sherwood ER. Targeting immune cell checkpoints during sepsis. Int J Mol Sci. 2017; 18: 2413.

151. Inoue S, Bo L, Bian J, Unsinger J, Chang K, Hotchkiss RS. Dose-dependent effect of anti-CTLA-4 on survival in sepsis. Shock. 2011; 36: 38-44.

152. Chen CW, Mittal R, Klingensmith NJ, Burd EM, Terhorst C, Martin GS, Coopersmith CM, Ford ML. Cutting edge: 2B4-mediated coinhibition of CD4(+) T cells underlies mortality in experimental sepsis. J Immunol. 2017; 199: 1961-6.

153. Boomer JS, Shuherk-Shaffer J, Hotchkiss RS, Green JM. A prospective analysis of lymphocyte phenotype and function over the course of acute sepsis. Crit Care. 2012; 16: R112.

154. Ajina A, Maher J. Strategies to address chimeric antigen receptor tonic signaling. Mol Cancer Ther. 2018; 17: 1795-815.

155. Zhen A, Peterson CW, Carrillo MA, et al. Long-term persistence and function of hematopoietic stem cell-derived chimeric antigen receptor $\mathrm{T}$ cells in a nonhuman primate model of HIV/AIDS. PLoS Pathog. 2017; 13: e1006753.

156. Leibman RS, Richardson MW, Ellebrecht CT, et al. Supraphysiologic control over HIV-1 replication mediated by CD8 T cells expressing a re-engineered CD4-based chimeric antigen receptor. PLoS Pathog. 2017; 13: e1006613.

157. Herzig E, Kim KC, Packard TA, et al. Attacking latent HIV with convertibleCAR-T cells, a highly adaptable killing platform. Cell. 2019; 179: 880-894.e10

158. Anthony-Gonda K, Bardhi A, Ray A, et al. Multispecific anti-HIV duoCAR-T cells display broad in vitro antiviral activity and potent in vivo elimination of HIV-infected cells in a humanized mouse model. Sci Transl Med. 2019; 11: eaav5685.

159. Zhen A, Carrillo MA, Kitchen SG. Chimeric antigen receptor engineered stem cells: a novel HIV therapy. Immunotherapy. 2017; 9: 401-10.

160. Krebs K, Bottinger N, Huang LR, et al. T cells expressing a chimeric antigen receptor that binds hepatitis $\mathrm{B}$ virus envelope proteins control virus replication in mice. Gastroenterology. 2013; 145: 456-65.

161. Kah J, Koh S, Volz T, Ceccarello E, Allweiss L, Lutgehetmann M, Bertoletti A, Dandri M. Lymphocytes transiently expressing virus-specific T cell receptors reduce hepatitis B virus infection. J Clin Invest. 2017; 127: 3177-88.

162. Festag MM, Festag J, Frassle SP, Asen T, Sacherl J, Schreiber S, Muck-Hausl MA, Busch DH, Wisskirchen K, Protzer U. Evaluation of a fully human, hepatitis $\mathrm{B}$ virus-specific chimeric antigen receptor in an immunocompetent mouse model. Mol Ther. 2019; 27: 947-59.

163. Proff J, Brey CU, Ensser A, Holter W, Lehner M. Turning the tables on cytomegalovirus: targeting viral $F_{C}$ receptors by CARs containing mutated CH2-CH3 IgG spacer domains. J Transl Med. 2018; 16: 26.

164. Park JY, Shin DJ, Lee SH, Lee JJ, Suh GH, Cho D, Kim SK. The anti-canine distemper virus activities of ex vivo-expanded canine natural killer cells. Vet Microbiol. 2015; 176: 239-49.

165. Verity R, Okell LC, Dorigatti I, et al. Estimates of the severity of coronavirus disease 2019: a model-based analysis. Lancet Infect Dis. 2020; 20: 669-77.

166. Pinti M, Appay V, Campisi J, Frasca D, Fulop T, Sauce D, Larbi A, Weinberger B, Cossarizza A. Aging of the immune system: Focus on inflammation and vaccination. Eur J Immunol. 2016; 46: 2286-301.

167. Li J, Li H, Mao H, et al. Impaired NK cell antiviral cytokine response against influenza virus in small-for-gestational-age neonates. Cell Mol Immunol. 2013; 10: $437-43$.

168. Sadighi Akha AA. Aging and the immune system: An overview. J Immunol Methods. 2018; 463: 21-6.

169. Gayoso I, Sanchez-Correa B, Campos C, Alonso C, Pera A, Casado JG, et al. Immunosenescence of human natural killer cells. J Innate Immun. 2011; 3: 337-43.

170. Gounder SS, Abdullah BJJ, Radzuanb N, Zain F, Sait NBM, Chua C, et al. Effect of aging on NK cell population and their proliferation at ex vivo culture condition. Anal Cell Pathol (Amst). 2018; 2018: 7871814.

171. Lutz CT, Karapetyan A, Al-Attar A, Shelton BJ, Holt KJ, Tucker JH, et al. Human NK cells proliferate and die in vivo more rapidly than $\mathrm{T}$ cells in healthy young and elderly adults. J Immunol. 2011; 186: 4590-8.

172. Le Garff-Tavernier M, Beziat V, Decocq J, Siguret V, Gandjbakhch F, Pautas E, et al. Human NK cells display major phenotypic and functional changes over the life span. Aging Cell. 2010; 9: 527-35.

173. Lopez-Verges S, Milush JM, Pandey S, York VA, Arakawa-Hoyt J, Pircher H, et al. CD57 defines a functionally distinct population of mature NK cells in the human CD56dimCD16+ NK-cell subset. Blood. 2010; 116: 3865-74.

174. Netea MG, Giamarellos-Bourboulis EJ, Dominguez-Andres J, Curtis N, van Crevel R, van de Veerdonk FL, Bonten M. Trained immunity: a tool for reducing susceptibility to and the severity of SARS-CoV-2 infection. Cell. 2020; 181: 969-77.

175. Yang F, Shi S, Zhu J, Shi J, Dai K, Chen X. Analysis of 92 deceased patients with COVID-19. J Med Virol. 2020; 92: 2511-5.

176. Cui W, Fan Y, Wu W, Zhang F, Wang JY, Ni AP. Expression of lymphocytes and lymphocyte subsets in patients with severe acute respiratory syndrome. Clin Infect Dis. 2003; 37: 857-9.

177. Tan L, Wang Q, Zhang D, Ding J, Huang Q, Tang YQ, Miao H. Lymphopenia predicts disease severity of COVID-19: a descriptive and predictive study. Signal Transduct Target Ther. 2020; 5: 33.

178. He R, Lu Z, Zhang L, Fan T, Xiong R, Shen X, Feng H, Meng H, Lin W, Jiang $\mathrm{W}$, Geng $\mathrm{Q}$. The clinical course and its correlated immune status in COVID-19 pneumonia. J Clin Virol. 2020; 127: 104361.

179. Zheng M, Gao Y, Wang G, Song G, Liu S, Sun D, Xu Y, Tian Z. Functional exhaustion of antiviral lymphocytes in COVID-19 patients. Cell Mol Immunol. 2020; $17: 533-5$.

180. Yaqinuddin A, Kashir J. Innate immunity in COVID-19 patients mediated by NKG2A receptors, potential treatment using Monalizumab, Cholroquine, antiviral agents. Med Hypotheses. 2020; 140: 109777.

181. Han H, Xu Z, Cheng X, Zhong Y, Yuan L, Wang F, et al. Descriptive, retrospective study of the clinical characteristics of asymptomatic COVID-19 patients. mSphere. 2020; 5: e00922-20.

182. Carsetti R, Zaffina S, Piano Mortari E, Terreri S, Corrente F, Capponi C, et al. different innate and adaptive immune responses to SARS-CoV-2 infection of asymptomatic, mild, and severe cases. Front Immunol. 2020; 11: 610300.

183. Maucourant C, Filipovic I, Ponzetta A, Aleman S, Cornillet M, Hertwig L, et al. Natural killer cell immunotypes related to COVID-19 disease severity. Sci Immunol. 2020; 5: eabd6832.

184. Bortolotti D, Gentili V, Rizzo S, Rotola A, Rizzo R. SARS-CoV-2 spike 1 protein controls natural killer cell activation via the HLA-E/NKG2A pathway. Cells. 2020; 9: 1975.

185. Cooper MD, Alder MN. The evolution of adaptive immune systems Cell. 2006; 124: $815-22$

186. Mancini M, Vidal SM. Mechanisms of natural killer cell evasion through viral adaptation. Annu Rev Immunol. 2020; 38: 511-39.

187. Hammer Q, Romagnani C. About training and memory: NK-cell adaptation to viral infections. Adv Immunol. 2017; 133: 171-207.

188. Paust S, Gill HS, Wang BZ, et al. Critical role for the chemokine receptor CXCR6 in NK cell-mediated antigen-specific memory of haptens and viruses. Nat Immunol. 2010; 11: 1127-35.

189. Lee J, Zhang T, Hwang I, Kim A, Nitschke L, Kim M, Scott JM, Kamimura Y, Lanier LL, Kim S. Epigenetic modification and antibody-dependent expansion of memory-like NK cells in human cytomegalovirus-infected individuals. Immunity. 2015; 42: 431-42.

190. Tong L, Assenmacher M, Zanker KS, Jahn P. Virus-specific peptide dependent NK cell cytotoxicity. Inflamm Allergy Drug Targets. 2014; 13: 128-33.

191. Jiang RD, Liu MQ, Chen $Y$, et al. Pathogenesis of SARS-CoV-2 in transgenic mice expressing human angiotensin-converting enzyme 2. Cell. 2020; 182: 50-58.e8. 